\title{
Earthquake Prediction Software on Global Scale
}

\author{
Haruhiro Shiraishi \\ Graduate School of Frontier Sciences, The University of Tokyo, Kashiwa, Japan \\ Email: ryoma.haruhiro@gmail.com
}

How to cite this paper: Shiraishi, H. (2022). Earthquake Prediction Software on Global Scale. Journal of Geoscience and Environment Protection, 10, 34-45.

https://doi.org/10.4236/gep.2022.103003

Received: February 11, 2022

Accepted: March 4, 2022

Published: March 7, 2022

Copyright (C) 2022 by author(s) and Scientific Research Publishing Inc. This work is licensed under the Creative Commons Attribution International License (CC BY 4.0).

http://creativecommons.org/licenses/by/4.0/

\section{(c) (i) Open Acces}

\begin{abstract}
Researchers developed an earthquake prediction software and evaluated its performance. This earthquake prediction software is suitable for short-term earthquake prediction. This approach relies on the deep involvement of water vapors that occur just before an earthquake caused by a decrease in pressure and an increase in temperature, leading to a $70.5 \%$ prediction accuracy within a month in Japan. In addition, we have tried to develop a new practical method to warn earthquakes for not only Japan but also global scale. In other words, this paper is dedicated to improving the short-term earthquake prediction software from Japan to global scale. In global scale, the prediction rate improved to $80.8 \%$.
\end{abstract}

\section{Keywords}

Dissociation, Earthquake, Global Scale, Machine Learning

\section{Introduction}

\subsection{Earthquake Explosion Theory}

Researchers hypothesized that earthquakes are based on the following definitions. Normally, the water of crystallization in the dissociation layer is stable. First, the position of the dissociation layer rises, and the degree of dissociation increases due to a decrease in pressure or an increase in ambient temperature (King, 1986; Goto, 1996; Ishida, 2013). When it rises sharply, a mixed gas of dissociated hydrogen gas and oxygen gas (dissociated water, also called explosive gas in science experiments) accumulates inside the magma chamber and the pressure increases. This can cause microcracks in the bedrock, which can trigger an earthquake precursor. Second, if the dissected gas in the plasma state moves at a high speed, MHD power generation may occur, and the underground cur- 
rent may be causing an electromagnetic precursor. The precursors may be the generation of telluric current, abnormalities caused by electromagnetic waves, and light emission phenomena (Davis \& Baker, 1965; Hayakawa, 1995; Araiza-Quijano \& Hernández-del-Valle, 1996; Bernard, Pinettes, Hatzidimitriou, Scordilis, Veis, \& Milas, 1997; Hayakawa \& Hobara, 2010). Since the dissociation reaction is a reaction that takes heat away, the ambient temperature of the magma chamber drops locally. Third, when the dissociation is completed, the heat from the surroundings moves, so the ambient temperature returns to the original temperature (Yamamoto, 2006). Then, when the explosion conditions of the roaring air are reached, it ignites and explodes. It can be said that this is the first stage of the earthquake. The direction of the explosion is determined by the shape of the magma chamber. After the explosion, the mixed gas returns to the supercritical water of crystallization, so the pressure drops, and the magma chamber collapses (Ishimoto, 1929). This is the second stage of the earthquake. The explosion releases heat and lowers the ionosphere to its pre-earthquake position. The seismic phenomenon has a peculiar phenomenon called push-pull phenomenon, but the first stage explosion creates a "push area" and the second stage creates a "pull area". The larger the earthquake, the more scars of the earthquake, called faults, appear at the boundary. In addition, if the dissected gas in the plasma state moves at a high speed, MHD power generation may occur, and the underground current may be causing an electromagnetic precursor. The researcher assumed that the clouds suggested by Manabe, Kagita, and Shou might be the gas caused by the decrease in pressure and increase in temperature (Manabe, 1981; Kagita, 1983; Shou, 1999). In addition, Aftershock activity is caused by repeated dissociation and detonation (Figure 1).

As clearly indicated in Figure 2, the researcher affirmed earthquake occurs in the following order. First, the dissociation layer, which is normally stable, moves to the upper layer due to the decrease in pressure and increase in temperature (King, 1986; Goto, 1996; Ishida, 2013). Second, as the dissociation layer rises, the water dissociates and the surrounding temperature drops (electrical precursors to earthquakes due to changes in hydrogen ion concentration, ionosphere, etc. (Davis \& Baker, 1965; Hayakawa, 1995; Araiza-Quijano \& Hernández-del-Valle, 1996; Bernard, Pinettes, Hatzidimitriou, Scordilis, Veis, \& Milas, 1997; Hayakawa \& Hobara, 2010). Third, when the temperature recovers, ignition occurs, followed by an earthquake (Yamamoto, 2006). Finally, magma rises because of depressurization caused by the binding reaction and the collapse of the magma pool

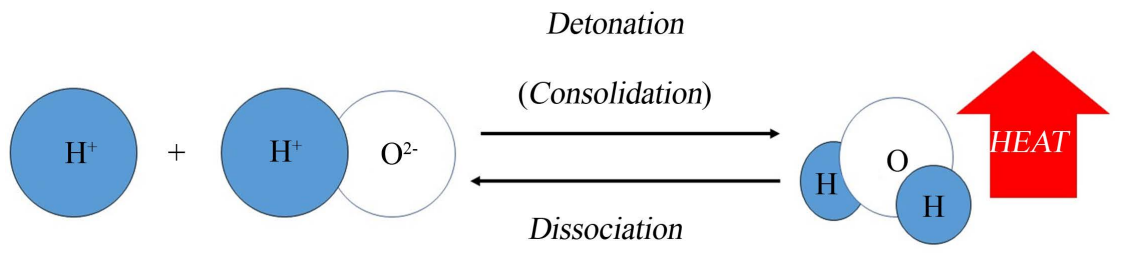

Figure 1. Chemical bonding formula of $\mathrm{H}_{2} \mathrm{O}$. 


\section{Earthquake anomaly mechanism}

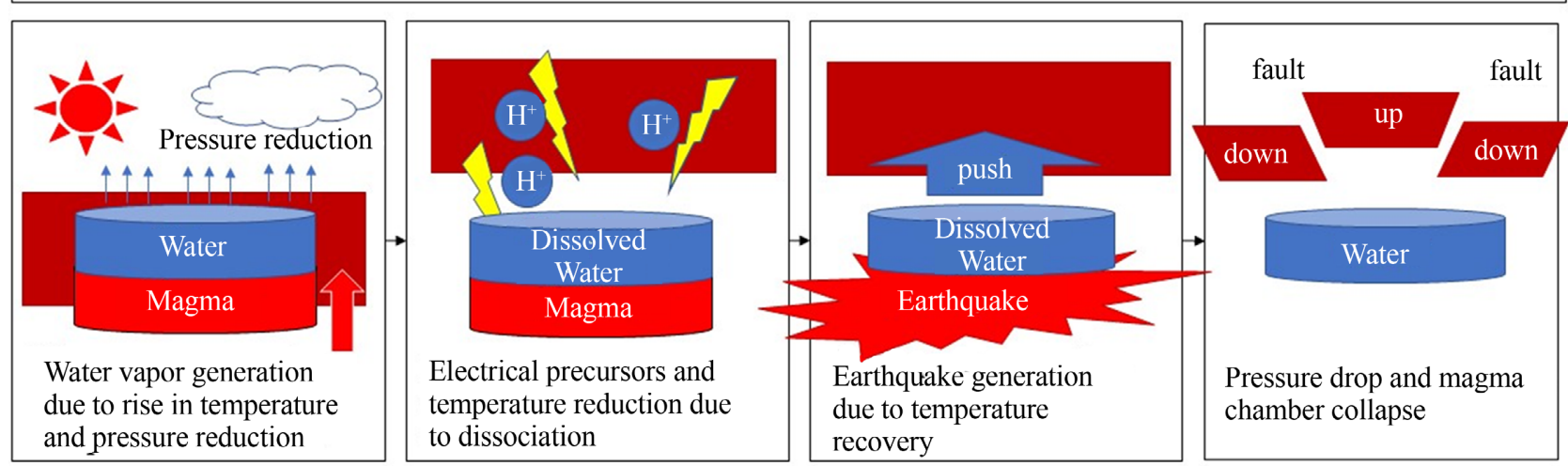

Figure 2. Mechanism of earthquake occurrence and its spectral phenomena.

(Ishimoto, 1929). The researcher assumed that the clouds suggested by Manabe, Kagita, and Shou might be the gas caused by the decrease in pressure and increase in temperature as described in the first step of earthquake occurrence (Manabe, 1981; Kagita, 1983; Shou, 1999). Due to the wide dissociation range of crystalline water, when the soil temperature rises, the dissociation layer rises and heats up, pushing steam to the surface (Manabe, 1981). This phenomenon can occur unexpectedly in places far from the epicentre, such as volcanic mountains and fault lines. Therefore, water vapor is easy to detect (Manabe, 1981; Kagita, 1980; Kagita, 1983). This theory is consistent with Ishida's theory that the normally stable dissociation layer moves to the upper layer as the pressure drops and the temperature rises (Ishida, 2013). Therefore, researchers sought to develop this software based on this mechanism, where water vapor is caused by a decrease in pressure and an increase in temperature.

\subsection{Earthquake Prediction Software}

A lot of software for earthquake prediction has been developed. Many of these papers are based on geology and seismology in the last 15 years. For example, in 2010, a study was conducted to model the behaviour of seismic time data based on seismic time data and non-parametric statistical tests to understand patterns useful for predicting medium to large earthquakes (Morales-Esteban, Martínez-Álvarez, Troncoso, Justo, \& Rubio-Escudero, 2010). In 2013, Francisco used neural networks to perform earthquake prediction to predict earthquakes in Chile (Reyes, Morales-Esteban, \& Martínez-Álvarez, 2013). This was an earthquake prediction method using statistical and geophysical models. In 2018, Amirul created a machine learning model for earthquake prediction that models the relationship between calculated seismic data and future seismic occurrences and calculates magnitude (Hoque, Raj, \& Saha, 2018). A type of recurrent neural network called long short-term memory (LSTM) was also used to model seismic sequences (Bhandarkar, Satish, Sridhar, Sivakumar, \& Ghosh, 2019). The overall feature of these latest studies was machine learning using training and test datasets, and 
the data were based on qualitative seismology. In addition, there is a little software research that explicitly mentions the relationship between earthquakes and weather. For example, Tan focused on and modeled a comprehensive analysis of shape and time series characteristics that could be used to identify pre-earthquake clouds from images of clouds from space (Tan, 2014). In addition, Shiraishi devised a model connecting meteorology and seismology from the theory of Ishimoto, and then developed and evaluated software based on quantitative observation data using meteorology in 2022 (Shiraishi, 2022). However, this software was limited to Japan and needed to be expanded globally. Therefore, in this research, we developed and evaluated the development of earthquake prediction software on a global scale.

\section{Method and Materials}

\subsection{Study Area}

The study area can be easily expanded by using satellite images. Therefore, the researcher conducted the global scale. The area captured by Himawari-8 is the range shown in Figure 3.

\subsection{Research Design}

To understand the characteristics of water vapor, researcher conducted a literature survey on water vapor and created teacher data. According to teacher data, most of them were linear in the plane because they erupted along the mountains or from the boundaries of the faults. However, on the global scale captured by satellite images, it was found that the earth has a spherical shape, so it has a linear shape near the centre and a distorted shape around the sphere. Therefore, the water vapor that appeared before the earthquake was detected as teacher data. Based on the template matching of teacher data and satellite images, we estimated the areas with high similarity as the epicentre. For scale, we adopted "similarity" using normalized cross-correlation.

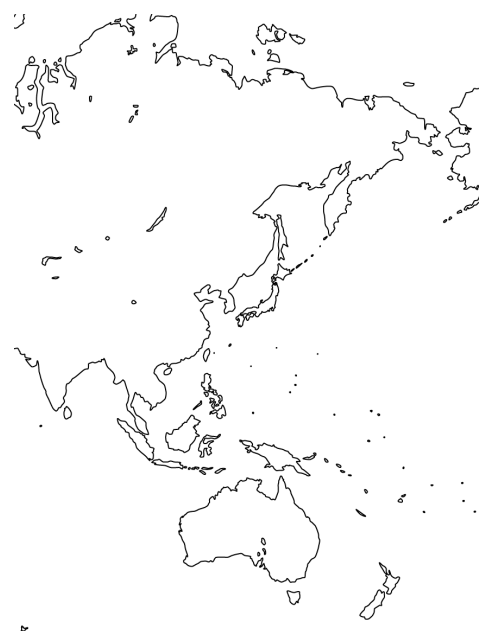

Figure 3. Global scale map captured by Himawari-8. 


\subsection{Sampling Method of Teacher Data}

For the image data, video image data from the National Institute of Information and Communications Technology (NICT) was used to create the teacher data. Next, the satellite video was cut at 240-minute intervals, and moving clouds were extracted by motion detection. Finally, cloud images over a certain area were trimmed and visually deciphered, and then stored as the teacher data.

\subsection{Teacher Data Sampling Method}

In this study, the teacher data were created by machine learning based on Shiraishi algorithm (Shiraishi, 2022). The flowchart of the program to judge the water vapors when sampling the teacher data is shown in Figure 4. The teacher data is classified into training data and test data by deciphering fault-type or volcanic range-type water vapor on global scale with machine learning. Finally, supervised learning should be performed and the water vapor data with correct answers should be sampled as the teacher data. When performing template matching with supervised data, the larger the number of samples, the easier it is to decipher the data. However, for accurate extraction of water vapor, it is important to learn the definition of water vapors and their types before sampling the data.

\subsection{Input of Water Vapor Image Data}

The program accepts images of water vapor as data. Here, thermal infrared images were downloaded from the National Institute of Information and Communications

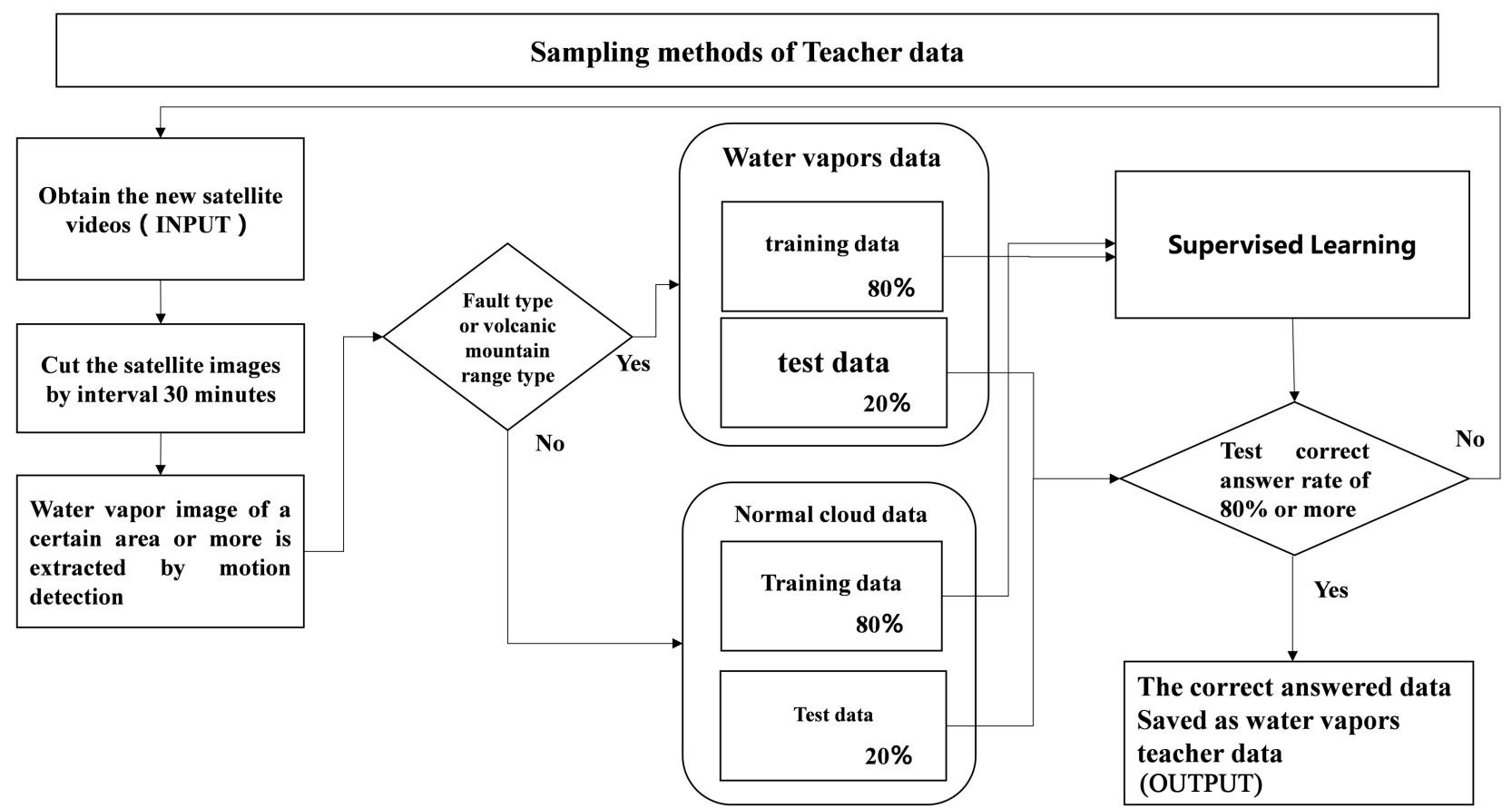

Figure 4. Sampling method of teacher data. The algorithm has been described in Sections 4.2 - 4.6 below: (2.5) Input of water vapor image data, (2.6) Input image for teacher data, (2.7) Filtering, (2.8) Template matching, and (2.9) Magnitude estimation (Shiraishi, 2022). 
Technology every $240 \mathrm{~min}$. In addition to this, the researcher used 1 years' data (from July 2015 to June 2016) to examine the correct response rate. Further, the researcher examined earthquakes that occurred around the world in 2022. Water vapor image data is shown in Figure 5.

\subsection{Image Input for Teacher Data}

Water vapor is defined as vapor with a temperature (pixel value) greater than a certain level as measured by thermal infrared images that stayed for a certain amount of time and are linear in shape, based on the theory of Manabe, Fan, that the closer water vapor is to the epicentre, the longer is the standstill time, and that they were found along fault lines and volcanic mountain ranges (Manabe, 1981; Fan, Chen, Yan, Gong, \& Wang, 2015) The examples of Water vapor over the ocean and land are shown in Figure 6.

\subsection{Image Input for Teacher Data}

Water vapor was filtered by separating them from ocean, lands, or normal clouds based on the brightness of the temperature.

$0 \leq \mathrm{P} \leq 49$ (Ocean or normal clouds);

$50 \leq \mathrm{P} \leq 100$ (Water vapor before earthquake);

$101 \leq \mathrm{P} \leq 255$ (Lands).

\subsection{Template Matching}

Template matching (Dong, Yongtao, \& Yajing, 2008; Brunelli, 2009) was applied to 10 pieces of supervised data, and the water vapor with the maximum similarity was extracted from the images. Normalized cross-correlation was used for calculating the similarity (Equation (1)).

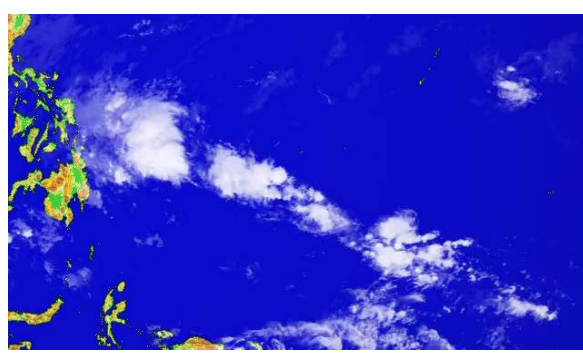

Figure 5. Water vapor image data before earthquake around Solomon Islands.
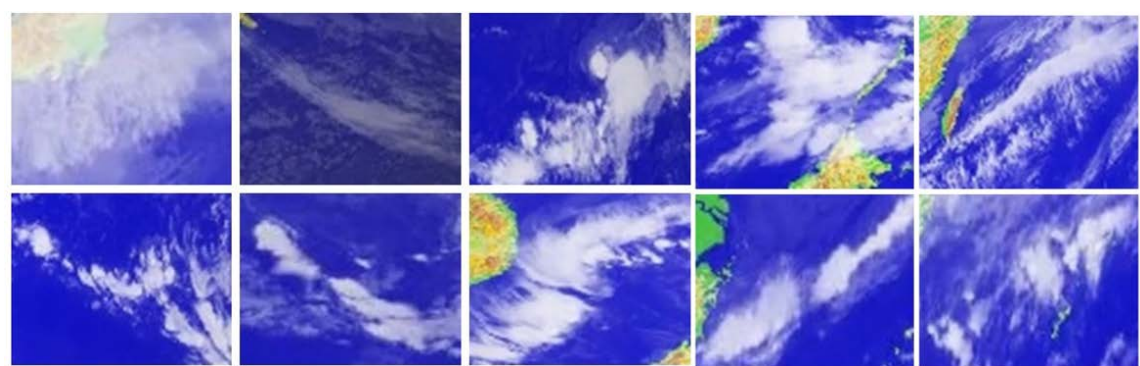

Figure 6. Examples of water vapor on global scale. 


$$
\operatorname{Result}(x, y)=\frac{\sum_{i, j}\left(T^{\prime}(i, j) \cdot I^{\prime}(x+i, y+j)\right)}{\sqrt{\sum_{i, j} T^{\prime}(i, j)^{2} \cdot \sum_{i, j} I^{\prime}(x+i, y+j)^{2}}}=\frac{(u-\bar{u})(v-\bar{v})}{\|u-\bar{u}\|\|v-\bar{v}\|}
$$

\subsection{Magnitude Estimation}

The normalized cross-correlation coefficient was used to estimate the magnitude (Equation (2)).

$$
M=C 1 \times R+C 2
$$

where $M$ is the magnitude, $R$ is the similarity in normalized cross-correlation, and $C 1$ and $C 2$ are the coefficients. Here, the researcher adopted $C 1=4$ and $C 2$ $=3.85(M \geq 6.0)$, which were obtained through experiments.

\subsection{Statistical Methods}

For the calculation of the target rate, the matrix of prediction rate and success rate was used, which is very commonly used in statistics.

\section{Results}

\subsection{Evaluation for Earthquake Predictions}

The researcher successfully assessed earthquake that occurred in the global scale from July 2015 to June 2016 within 31 days. The magnitudes were more than $90 \%$ accurate with an error range of \pm 0.7 , i.e., if the magnitude, place of occurrence, and time are considered, the accuracy is $42 / 52=0.8076(80.8 \%)$. For the 2021 earthquake, the researcher also succeeded in detecting precursors for several earthquakes. This result is shown in Table 1 and Table 2. The magnitude estimate (M $6.0 \pm 0.7)$ was correct, and it leads us to the location and time.

\subsection{Successful Prediction Example of the Taiwan Earthquake}

For the verification of water vapors, we utilized data from past satellite images. The verification example shown in Figure 7 is the result of analysis using satellite images taken 18 days before an earthquake that struck Taiwan region in 2011. In this study, to construct a global model, we developed and verified a global model based on the spherical Himawari-8.

Table 1. Successful rate and prediction rate of earthquake prediction in 31 days $(M \geq$ $6.0)$.

\begin{tabular}{cccc}
\hline & \multicolumn{3}{c}{ Results } \\
\cline { 2 - 4 } & Earthquake & No Earthquakes & Sum \\
\hline Water vapor & 0.81 & 0.19 & $(52 / 52)$ \\
No water vapor & $(42 / 52)$ & $(10 / 52)$ & $(68 / 68)$ \\
Sum & 0.40 & 0.60 & $(120 / 120)$ \\
\hline
\end{tabular}




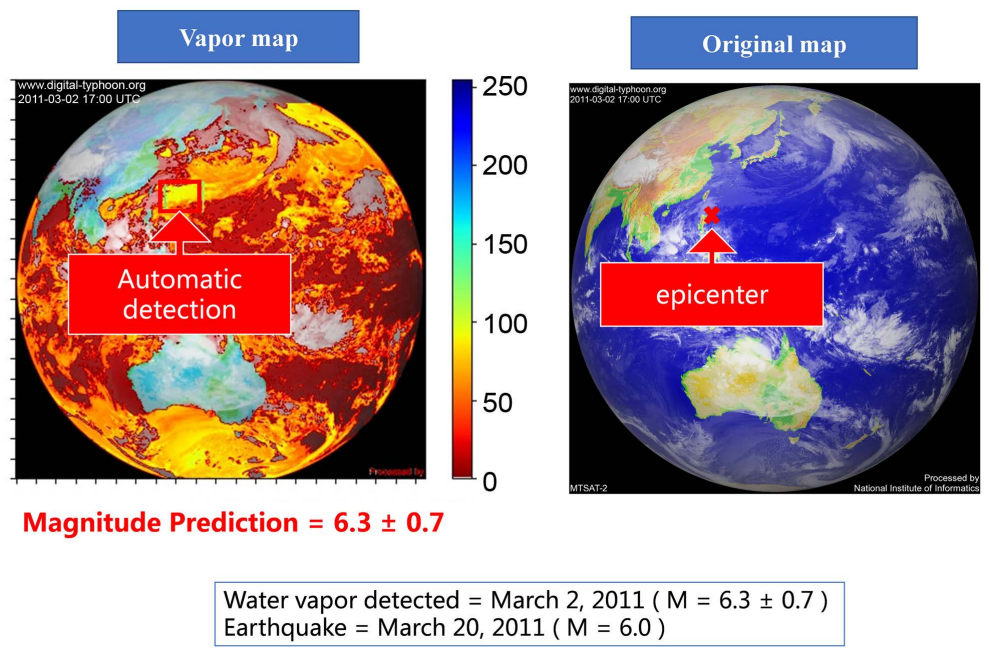

Figure 7. Image capturing the Taiwan earthquake [M 6.0, March 2, 2011 (UTC)].

Table 2. Examples of earthquake predictions.

\begin{tabular}{|c|c|c|c|c|c|c|c|}
\hline & & Prediction & & & Results & & Success \\
\hline & Date & Magnitude & Place & Date & Magnitude & Place & or failure \\
\hline 1 & $\begin{array}{c}1 / 7 / 2015 \\
- \\
1 / 8 / 2015\end{array}$ & $5.25-6.65$ & Indonesia & $12 / 7 / 2015$ & 5.5 & Indonesia & Success \\
\hline 2 & $\begin{array}{c}12 / 10 / 2015 \\
- \\
12 / 11 / 2015\end{array}$ & $5.25-6.25$ & $\begin{array}{c}\text { Tohoku, } \\
\text { Japan }\end{array}$ & $2 / 11 / 2016$ & 5.4 & $\begin{array}{c}\text { Tohoku, } \\
\text { Japan }\end{array}$ & Success \\
\hline 3 & $\begin{array}{c}1 / 4 / 2016 \\
- \\
1 / 5 / 2016\end{array}$ & $5.55-6.95$ & Vanuatu & $18 / 4 / 2016$ & 5.9 & Vanuatu & Success \\
\hline 4 & $\begin{array}{c}26 / 6 / 2016 \\
- \\
26 / 7 / 2016\end{array}$ & $5.35-6.75$ & $\begin{array}{c}\text { South } \\
\text { of Japan }\end{array}$ & $30 / 7 / 2016$ & 7.7 & $\begin{array}{l}\text { Mariana } \\
\text { Islands }\end{array}$ & Fail \\
\hline 5 & $\begin{array}{c}29 / 6 / 2016 \\
- \\
29 / 7 / 2016\end{array}$ & $5.35-6.75$ & $\begin{array}{l}\text { Kermadec } \\
\text { Islands }\end{array}$ & $13 / 7 / 2016$ & 5.9 & $\begin{array}{c}\text { Kermadec } \\
\text { Islands }\end{array}$ & Success \\
\hline
\end{tabular}

\section{Discussion}

\subsection{Difference between Japan and Global Model}

The big difference between the Japanese model and the global model is its form. The map of the Japanese model (local model) is flat, while the map of the global model is spherical. Machine learning was performed because it is very difficult to calculate a suitable image of water vapor in a spherical model. In addition, since the pixel threshold also differs depending on the image shooting method and generation method, a value significantly different from the Japanese version (local version) was calculated. The difference between Japan and global model is 
shown in Figure 8.

\subsection{Software Information}

This software inputs teacher data on satellite images of water vapor generated before an earthquake and automatically predicts the location (within the frame), time (within one month), and scale (magnitude error \pm 0.7 ) of the earthquake. In addition, regarding the occurrence of earthquakes, we succeeded in improving the accuracy by involving thresholds and water vapor clouds in machine learning. The software in this study has the advantage that anyone can use it easily and even people who have no knowledge of earthquakes can predict earthquakes. In the future, we will work on disaster prevention from a global perspective so that the lives of many people, man-made objects, nature, etc. will not be lost by working to improve the software so that the damage caused by the earthquake can be mitigated as much as possible. This software has two types, a local version, and a global version.

\subsection{The Period from the Generation of Gas to the Occurrence of an Earthquake}

A histogram of the number of days it takes for an earthquake to occur after the gas is generated is shown in Figure 9. Earthquakes were most likely to occur 1 to 8 days (about a week) after the gas was generated. It was also found that the longer the number of days, the lower the ratio to the total number of days. In

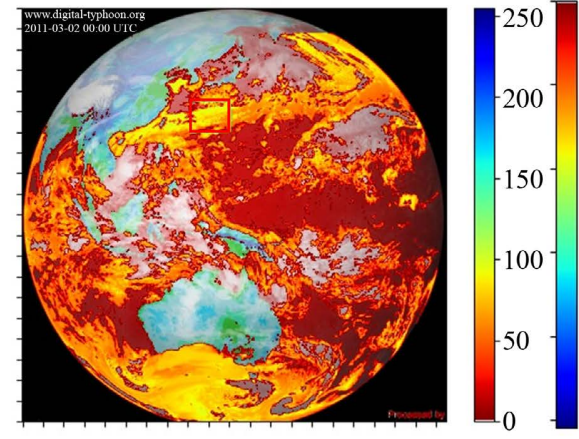

Magnitude Prediction $=6.4 \pm 0.7$

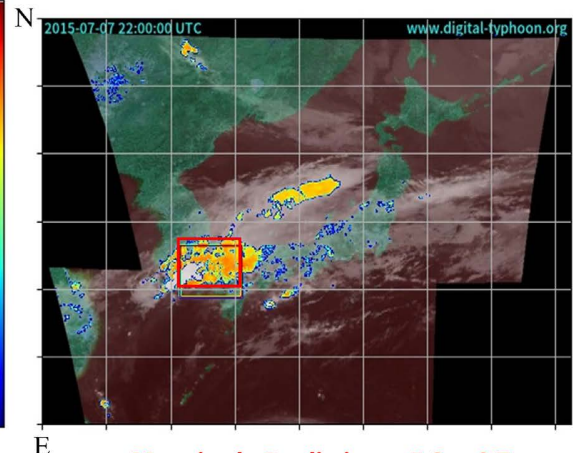

Magnitude Prediction $=5.3 \pm 0.7$

Figure 8. The difference between Japan and global model.

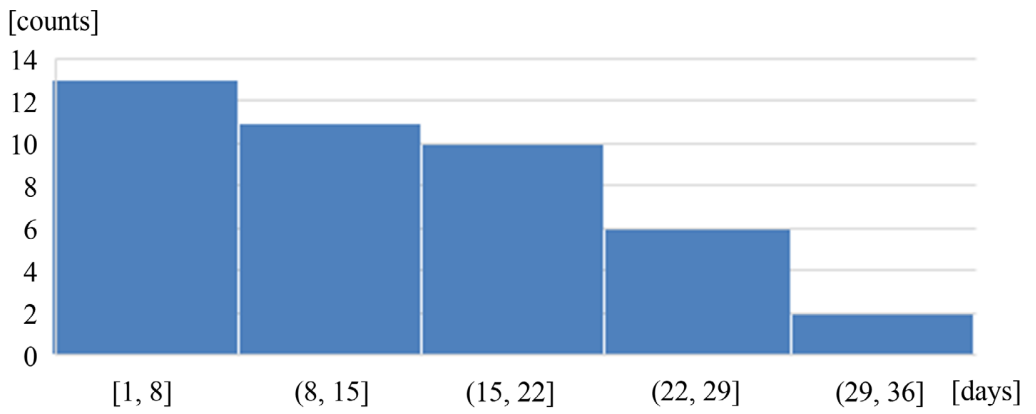

Figure 9. The period from the generation of gas to the occurrence of an earthquake. 
addition, 13/42 (31\%) within one week, 24/42 (57\%) within two weeks, and $34 / 42(81 \%)$ within three weeks from the generation of water vapor to the occurrence of an earthquake. It is known that 40/42 (95\%) earthquakes will occur within 4 weeks and 42/42 (100\%) earthquakes will occur within 5 weeks. This suggests that the shorter the period of ignition after the release of water vapor, the more likely it is that an earthquake will occur.

\section{Conclusion}

Shiraishi's Japan model found $70.5 \%$ prediction accuracy within a month using the water vapors software, which is comparable to Shou's $68 \%$ accuracy and the VAN method with $60 \%$ accuracy in Greek geo-currents. In addition, in the global model, $80.8 \%$ accuracy was achieved. This is a very high prediction rate compared to other studies. By combining the research results of the global model and Shiraishi's Japan model (local model), it will be possible to comprehensively evaluate the predicted distribution of earthquakes from a micro perspective and a macro perspective. This is a revolutionary invention that contributes to disaster-prone countries and is one of the ways to protect the lives and nature of many people.

\section{Acknowledgements}

The author wishes also to thank Shamik Kundu for his time in the initial proofreading of this article.

\section{Conflicts of Interest}

The author declares no conflicts of interest regarding the publication of this paper.

\section{References}

Araiza-Quijano, M. R., \& Hernández-del-Valle, G. (1996). Some Observations of Atmospheric Luminosity as a Possible Earthquake Precursor. Geofisica Internacional, 35, 403-408. https://doi.org/10.22201/igeof.00167169p.1996.35.4.532

Bernard, P., Pinettes, P., Hatzidimitriou, P. M., Scordilis, E. M., Veis, G., \& Milas, P. (1997). From Precursors to Prediction: A Few Recent Cases from Greece. Geophysical Journal International, 131, 467-477. https://doi.org/10.1111/j.1365-246X.1997.tb06590.x

Bhandarkar, T., Satish, N., Sridhar, S., Sivakumar, R., \& Ghosh, S. (2019). Earthquake Trend Prediction Using Long Short-Term Memory RNN. International Journal of Electrical \& Computer Engineering, 9, 1304-1312. https://doi.org/10.11591/ijece.v9i2.pp1304-1312

Brunelli, R. (2009). Template Matching Techniques in Computer Vision: Theory and Practice. John Wiley \& Sons. https://doi.org/10.1002/9780470744055

Davis, K., \& Baker, D. M. (1965). Ionospheric Effects Observed around the Time of the Alaskan Earthquake of March 28, 1964. Journal of Geophysical Research, 70, 2251-2253. https://doi.org/10.1029/JZ070i009p02251

Dong, J., Sun, Y. T., \& Zhao, Y. J. (2008). Design Pattern Detection by Template Match- 
ing. In L. M. Liebrock (Ed.), Proceedings of the 2008 ACM Symposium on Applied Computing (pp. 765-769). Association for Computing Machinery. https://doi.org/10.1145/1363686.1363864

Fan, J., Chen, Z., Yan, L., Gong, J., \& Wang, D. (2015). Research on Earthquake Prediction from Infrared Cloud Images. In J. G. Liu, \& H. Sun (Eds.), MIPPR 2015: Remote Sensing Image Processing, Geographic Information Systems, and Other Applications (Vol. 9815, p. 98150E). International Society for Optics and Photonics. https://doi.org/10.1117/12.2203657

Goto, K. (1996). Extraction of Earthquake Clouds from Artificial Satellite Images-Searching for the Possibility of Earthquake Prediction from Space. In Global Environmental Engineering Research Group (Ed.), Proceedings of the 2nd Space Environment Monitoring Conference (pp. 1-4). The University of Tokyo.

Hayakawa, M. (1995). Reception of Earthquake Precursor Radio Waves and Earthquake Prediction. Chemistry, 50, 543-545. (In Japanese)

Hayakawa, M., \& Hobara, Y. (2010). Current Status of Seismo-Electromagnetics for Short-Term Earthquake Prediction. Geomatics, Natural Hazards and Risk, 1, 115-155. https://doi.org/10.1080/19475705.2010.486933

Hoque, A., Raj, J., \& Saha, D. A. (2018). Approaches of Earthquake Magnitude Prediction Using Machine Learning Techniques. In S. Deb, N. Kar, F. Lin, \& A. Saha (Eds.), International Conference on Computational Intelligence \& IoT (ICCIIoT) (pp. 1-5). International Association of Academicians (IAASSE). https://doi.org/10.2139/ssrn.3513365

Ishida, A. (2013). Giant Earthquakes Are Caused by the Implosion of "Dissociated Water".

Ishimoto, S. (1929). On the Mechanism of Earthquake Occurrence. Bulletin of the Earthquake Research Institute, 6, 127-147.

Kagita, C. (1980). This Is the Cloud of Earthquakes, and the Cloud Does Not Make a Mistake.

Kagita, C. (1983). This Is Cloud of Earthquake. NGS.

King, C. Y. (1986). Gas Geochemistry Applied to Earthquake Prediction: An Overview. Journal of Geophysical Research: Solid Earth, 91, 12269-12281. https://doi.org/10.1029/JB091iB12p12269

Manabe, D. (1981). Earthquakes Can Be Predicted by the Shape and Color of Clouds and Haze.

Morales-Esteban, A., Martínez-Álvarez, F., Troncoso, A., Justo, J. L., \& Rubio-Escudero, C. (2010). Pattern Recognition to Forecast Seismic Time Series. Expert Systems with Applications, 37, 8333-8342. https://doi.org/10.1016/j.eswa.2010.05.050

Reyes, J., Morales-Esteban, A., \& Martínez-Álvarez, F. (2013). Neural Networks to Predict Earthquakes in Chile. Applied Soft Computing, 13, 1314-1328. https://doi.org/10.1016/j.asoc.2012.10.014

Shiraishi, H. (2022). Developing and Validating Earthquake Prediction Software. International Journal of Engineering and Techniques, 8, 63-69.

Shou, Z. H. (1999). Earthquake Clouds, a Reliable Precursor. Science \& Utopia, 64, 53-57.

Tan, X., Ma, Y., Jiao, Z., Su, L., Ma, A., Hou, J., \& Yan, L. (2014). Modeling Pre-Earthquake Cloud Shape from Remote-Sensing Images. In Q. H. Weng, P. Gamba, G. Xian, G. X. Wang, \& J. J. Zhu (Eds.), 2014 Third International Workshop on Earth Observation and Remote Sensing Applications (EORSA) (pp. 470-474). IEEE.

https://doi.org/10.1109/EORSA.2014.6927935

Yamamoto, H. (2006). An Explanation of Earthquakes by the Black Light Process and 
Hydrogen Fusion. In A. Takahashi, K. I. Ota, \& Y. Iwamura (Eds.), Condensed Matter Nuclear Science (pp. 577-581). World Scientific.

https://doi.org/10.1142/9789812772985_0062 